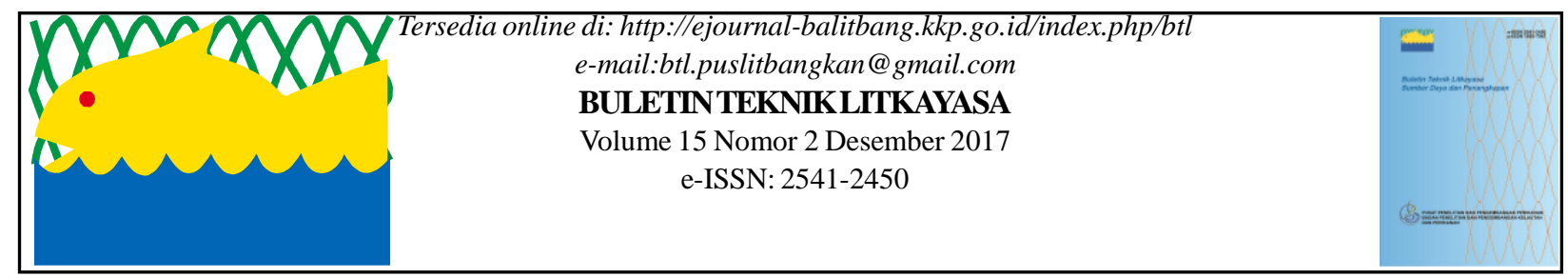

\title{
KARAKTERISTIK DAN HASIL TANGKAPAN BEBERAPA ALAT TANGKAP DOMINAN DI SUNGAI MUSI BAGIAN HILIR (ESTUARIA) SUMATERA SELATAN
}

\author{
Mirna Dwirastina dan Dewi Apriyanti \\ Teknisi Litkayasa Balai Penelitian Perikanan Perairan Umum \\ Teregistrasi I tanggal: 30 November 2017; Diterima setelah perbaikan tanggal: 08 Desember 2017; \\ Disetujui terbit tanggal: 13 Desember 2017
}

\section{PENDAHULUAN}

Menurut Juandana (2008) bahwa sungai merupakan jenis perairan dengan system terbuka yang sangat tergantung pada keadaan lingkungan sekitarnya. Sungai merupakan badan air yang kontiyu, keadaan di bagian hilir merupakan kelanjutan dari kejadian-kejadian di bagian hulu yang dapat menggambarkan perubahan struktur dan fungsi komunitas sepanjang sungai. Perairan estuaria merupakan aliran sungai yang mengalir kearah hilir dari suatu aliran sungai yang berperan sebagai perangkap hara dan polutan dari aliran sungai ruas hulu. Karakteristik habitat sangat khas dan dinamis terutama salinitas, kekeruhan dan arus air karena dipengaruhi oleh pasang surut air laut. Di Sumatera Selatan perairan estuaria ini terdapat di bagian hilir Sungai Musi, Sungai Upang, Sungai Banyuasin, dan Sungai Sembilang. Ekosistem estuaria yang berhubungan dengan Selat Bangka. Daerah estuaria merupakan pusat perikanan tangkap dengan berbagai jenis alat tangkap untuk menangkap ikan dan udang.

Menurut Nurdawati et al., (2010) bahwa penangkapan di daerah estuaria di Sungai Musi sangat berkembang dan menggunakan 14 jenis alat tangkap yang didominasi oleh alat tangkap tuguk dan blad. Tujuan penulisan makalah ini adalah menyajikan karakteristik alat tangkap dominan dan hasil tangkapannya di perairan estuaria Sungai Musi, Sumatera Selatan.

\section{POKOK BAHASAN \\ Bahan dan Metode}

Penelitian ini dilakukan pada Mei, Juni, Juli dan Agustus 2006. Metode penelitian adalah survey, yaitu melakukan pengamatan langsung dengan mengikuti kegiatan nelayan. Data yang dikumpulkan meliputi karakteristik alat tangkap, cara pengoperasian dan jenis-jenis hasil tangkapan. Lokasi penelitian disajikan pada gambar 1 .

\section{HASIL DAN PEMBAHASAN}

Alat tangkap dominan yang digunakan di perairan Sungai Musi bagan hilir (estuaria) adalah jarring kantong (trammel net), blad (beach barrier trap) dan tuguk tancap

\section{Jaring Kantong ( Trammel Net)}

Jaring kantong (Gambar 2) terdiri dari tiga lapis jaring (triple walled net), dua lapis di sebelah luar berukuran mata jaring lebih besar daripada mata jaring bagian dalam sesuai dengan spesifikasi pada Tabel 1. Kontruksi ini menyebabkan ikan atau udang yang menerobos lapisan luar akan terperangkap dan tersangkut pada lapisan dalam yang membentuk kantong.



Gambar 1. Lokasi Penelitian.

Korespondensi penulis:

Jalan Gubernur H.A Bastari No.08, Jakabaring - Palembang

Sumatera Selatan, 30125 


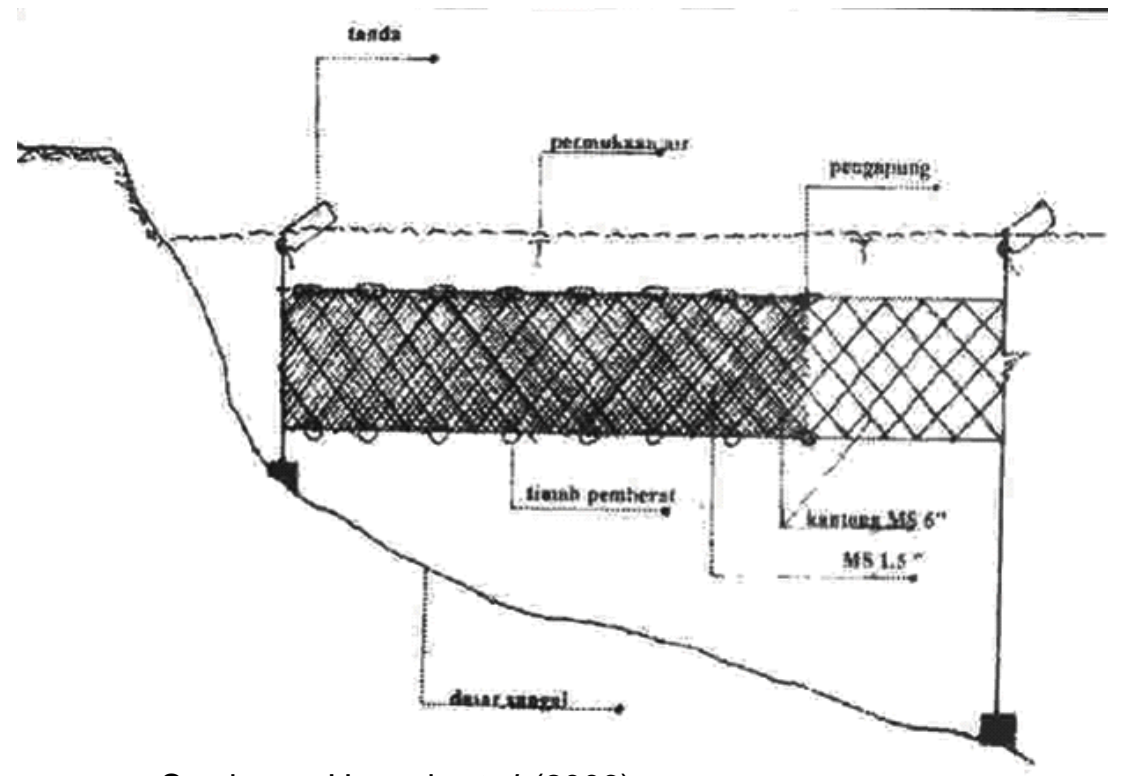

Sumber: Husnah et al. (2006)

Gambar 2. Karakteristik alat tangkap jaring kantong.

Tabel 1. Dimensi umum alat tangkap jaring kantong yang dioperasikan di Sungai Musi bagian hilir.

\begin{tabular}{|c|c|c|c|c|c|c|c|c|c|}
\hline No & Jenis & Bahan & $\begin{array}{c}\text { Ukuran } \\
\text { Mata } \\
(\mathrm{mm})\end{array}$ & $\begin{array}{l}\text { Panjang } \\
\text { (m) }\end{array}$ & $\begin{array}{c}\text { Dalam } \\
(\mathrm{m})\end{array}$ & $\underset{(\mathrm{mm})}{\mathrm{I}}$ & Tipe & Jml & HR \\
\hline 1 & Lapisan Luar & $\begin{array}{l}\text { PA } 210 \mathrm{~d} 6 \\
\text { PA2 } 10 \mathrm{~d} 2\end{array}$ & 100-175 & 18 & 1.33 & & & & $\begin{array}{l}0.5 \\
1\end{array}$ \\
\hline 2 & Lapisan Dalam & $\begin{array}{l}\text { PE d3 } \\
\text { PE }\end{array}$ & $3.8-42.5$ & 18 & 1.67 & & & & $\begin{array}{l}0.4 \\
5\end{array}$ \\
\hline $\begin{array}{l}3 \\
4 \\
5 \\
6 \\
7\end{array}$ & $\begin{array}{l}\text { Srampat } \\
\text { Tali pelampung } \\
\text { Tali pemberat } \\
\text { Pelampung } \\
\text { Pemberat }\end{array}$ & $\begin{array}{l}\text { PE } \\
\text { Plastik } \\
\text { Timah }\end{array}$ & 40 & $\begin{array}{l}18 \\
18-23 \\
22-26 \\
\text { Y-2/GPIRL }\end{array}$ & 6.15 & $\begin{array}{l}5 \\
2\end{array}$ & $\begin{array}{l}\text { Silinder } \\
\text { Gendang }\end{array}$ & $\begin{array}{l}2 \\
2 \\
43 \\
200\end{array}$ & $\begin{array}{l}0.4 \\
5\end{array}$ \\
\hline
\end{tabular}

Jaring kantong dioperasikan menggunakan perahu kayu dengan ukuran panjang $6-10$ meter dan lebar 1,5 - 2 meter, mesin perahu 5,5 PK. Perahu jaring kantong ini dilengkapi kotak berinsulasi ukuran 0.8 $\mathrm{m}^{3}$ dengan menggunakan pengawet es batu.Jumlah nelayan yang mengoperasikan 1 - 3orang. Jumlah jaring dalam tiap perahu sekitar 7 utas, dimana panjang tiap utas 30 meter.

Cara Pengoperasian adalah sebagai berikut:

1. Bersifat menetap, jaring diset didasar perairan dengan salah satu bagian jaring diikatkan di tepian sungai, sedangkan sisi yang lain ditebar memotong badan sungai. Setelah $3-4$ jam, jaring ditarik dan satu persatu ikan yang tertangkap dilepaskan dari jaring.

2. Bersifat hanyut dengan cara memasang jaring pada bagian dasar sungai dengan tidak mengaitkan salah satu ujung jaring dan membiarkannya terhanyut terbawa arus air sungai, sehingga jaring menyerupai sweeping perairan. Biasanya nelayan memilih kondisi air tidak berarus terlalu kuat. Hal ini dilakukan agar proses pemasangan dan pengangkatan jaring lebih efisien. Setelah jaring mencapai jarak tertentu yang ditentukan oleh nelayan sendiri dari tempatnya ditebar, maka jaring ditarik dan hasil ikan diambil dari badan jaring. Jenis-jenis ikan hasil tangkapan disajikan pada Table 2. 
Tabel 2. Hasil tangkapan ikan menggunakan alat tangkap jaring kantong di Perairan Sungai Musi bagian hilir.

\begin{tabular}{|c|c|c|}
\hline No & Jenis Ikan & Nama Latin \\
\hline 1 & Dukang & Arius stormii \\
\hline 2 & Juara & Pangasius polyuronodon \\
\hline 3 & Bulu ayam & Colia borneensis \\
\hline 4 & Palak batu & Johnius coitor \\
\hline 5 & Janggutan & Polynemus dubius \\
\hline 6 & Lidah & Cynoglossus feldmanni \\
\hline 7 & Sepengkah & Parambasis wolfii \\
\hline 8 & Lumajang & Cyclocheilichthys enoplos \\
\hline 9 & Patin & Pangasius jambal \\
\hline 10 & Lais & Kryptopterus sp \\
\hline 11 & Lele & Clarias spp \\
\hline 12 & Gulamo & Johnius belengeri \\
\hline 13 & Tikusan & Bagroides melapterus \\
\hline 14 & Belut Tulang & Cryptopterus apogon \\
\hline 15 & Pari & Himantura signifier \\
\hline 16 & Coli & Albulichthys albuloides \\
\hline 17 & Sihitam & Labeo chrysophekadion \\
\hline 18 & Sembilang & Paraplotosus albilabris \\
\hline 19 & Kakap batu & Lates calcarifer \\
\hline 20 & Baung & Hemibagrus nemurus \\
\hline 21 & Sepatung & Puntioplites bulu \\
\hline 22 & Tirusan & Boesemania microlepis \\
\hline 23 & Tilan & Mastecembelus erythrotaenia \\
\hline 24 & Lundu & Mystus gulio \\
\hline 25 & Bengalan & Puntioplites bulu \\
\hline 26 & Aro & Osteochilus sp \\
\hline 27 & Lampam & Barbonymus schwanenfeldii \\
\hline
\end{tabular}

\section{Blad (Beach Barrier Trap)}

Alat ini dibuat dari jarring dengan ukuran mata jaring $4.0 \mathrm{~mm}$, panjang $100-300 \mathrm{~m}$, lebar 2.0-3.0 m dan tinggi 3 meter (Gambar 3). Bagian Bawah dan atas jaring dilengkapi tali ris bahan PE $5.0 \mathrm{~mm}$. Agar jaring bisa terbentang vertical saat dioperasikan pada setiap jarak 4-5 meter dipasang tiang kayu atau bamboo dengan diameter 10-15. Blad merupakan alat tangkap pasif. Target tangkapan utam blad adalah udang baik udang laut (penaid) atau udang air tawar (Macrobrachium rosenbergii). Alat ini menagkap ikan dengan cara menjebak atau mengurung ikan dan udang yang beruaya secara lateral ke bagian pinggiran sungai sat air pasang.

\section{Tuguk Tancap}

Alat tangkap ini terdiri dari dua komponen utama yaitu kerangka pasangan batang kayu nibung yang dirakit sedemikian rupa untuk tempat memasang jaring kantong sebagai komponen utama untuk menangkap ikan. Batang kayu nibung digunakan sebagai tiang utama, tiang penyangga, dan tempat pijakan nelayan saat operasional. Jaring kantong berbentuk kerucuk dengan kisaran panjang 6-9m, ukuran bukaa depan $3 \times 3 \mathrm{~m}$, serta mesh size jaring terdiri dari lima ukuran mengecil mulai dari depan setiap panjang 2 meter yaitu 2.0 inci, $1.5 \mathrm{inci}, 1$ inci, 0.50 inci, dan 0.25 inci. 


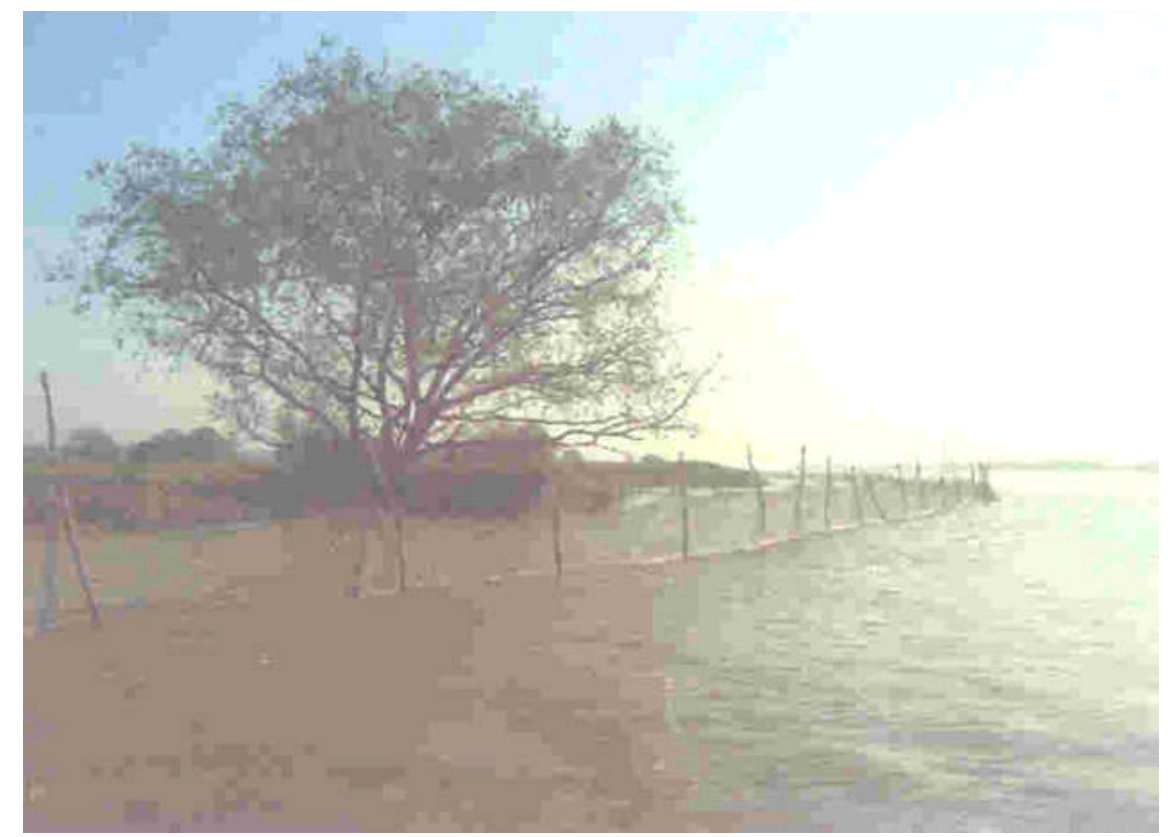

Sumber: Husnah et al, (2006)

Gambar 3. Karakteristik alat tangkap blad (Beach Barrier Trap).

Tuguk tancap atau tuguk baris (Gambar 4) dipasang memanjang arah memotong badan sungai. Baris tuguk dipasang mulai 10-30 meter dari tepian sungai, maksimum sampai sepertiga lebar sungai dan tidak boleh menutup atau menggangu alur transportasi kendaraan air. Jarak antara baris tuguk dengan tuguk yang lain minimal 500 meter. Jarak antara tali ris bawah depan jaring tuguk dengan dasar perairan dan tali ris atas dengan permukaan perairan antara $0.5-$ 1.0 meter. Hal ini bertujuan untuk menghindari kotoran dasar dan permukaan perairan masuk jaring tuguk.



Sumber: Husnah et al., 2006

Gambar 4. Karakteristik alat tangkap tuguk tancap.

Tuguk bersifat pasif dan dioperasikan dengan memanfaatkan arus air pasang atau surut terutama pada arus air pasang. Tuguk menghadang ikan atau udang yang hanyut terbawa arus air, masuk jaring dan terkumpul pada ujung jaring kantong yang berbentuk kerucut yang berfungsi sebagai kantong pengumpul. Tuguk dioperasikan malam/siang hari waktu air pasang /surut. Hasil tangkapan tuguk tancap disajikan pada Table 3. 
Tabel 3. Jenis hasil tangkapan alat tangkap tuguk tancap di Sungai Musi Bagian Hilir

\begin{tabular}{lll}
\hline No & \multicolumn{1}{c}{ Jenis lkan } & Nama Latin \\
\hline 1 & Udang burung & Penaeus merguiensis \\
2 & Udang cat & Parapenaeopsis sp \\
3 & Udang petak & Oratosquilla sp \\
4 & Baji & Platycephalus sp \\
5 & Kepiting & Scylla serrata \\
6 & Lepu & Leptosynanceia asteroblepa \\
7 & Belumbungan & Otolithus rubber \\
8 & Sumpit & Toxotes microlepis \\
9 & Petek & Pampus argenteus \\
10 & Gulamo keken & Pama pama \\
11 & Pirang putih & Lycothrissa crocodiles \\
12 & Bilis & \\
13 & Buntal & Tetraodon sp \\
14 & Selincing & Pseudapocrytes lonceolatus \\
15 & Duri & Arius polystaphylodon \\
16 & Belut tulang & Muranesox talabon \\
17 & Selontok & Bostrychus sinensis \\
18 & Belanak & Liza melinoptera \\
19 & Lidah panjang & \\
20 & Sepengkah & Ambassis kopsii \\
21 & Ubur-ubur & \\
22 & Janggutan & Polynemus longipectoralis \\
23 & Betutu & Oxyleotris marmorata \\
24 & Layur & Lepturacanthus savala \\
25 & Kiper & Scatophagus \\
26 & Lidah pendek & Cynoglassus feldmanni \\
\hline & & Gat \\
\hline
\end{tabular}

\section{KESIMPULAN}

Alat tangkap dominan yang digunakan di Sungai Musi bagian hilir adalah jaring kantong, blad dan tuguk tancap. Hasil tangkapan dari ketiga alat tangkap berbeda, yaitu jarring kantong didominasi oleh ikan, blad spesifik untuk menangkap udang laut dan air tawar, kemudian tangkapan tuguk tancap bervariasi dari udang, ikan dan non ikan lainnya, seperti diantaranya kepiting.

\section{DAFTAR PUSTAKA}

Juandana, S. (2008). Kualitas air sungai musi bagian hilir ditinjau dari karakteristik fisika-kimia perairan dan struktur komunitas fitoplankton. UNSRI. Palembang.
Husnah, S., Gautama, S., Nurdawati, S., \& Dharyati, E. (2006). Jenis, cara operasi dan penyebaran beberapa alat tangkap ikan di perairan Sungai Musi, Sumatera Selatan. Pusat Riset Perikanan Tangkap. Badan Riset Kelautan dan Perikanan.

Nurdawati, S. Rupawan., Makmur, S., \& Rais, A. H. (2010). Aktivitas perikanan tangkap di Sungai Musi dalam perikanan perairan Sungai Musi Sumatera Selatan. Balai Riset Perikanan Perairan Umum. Palembang. 